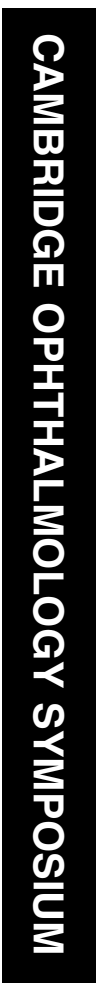

${ }^{1}$ Department of Tissue Tech., Ocular Surface Center, Ocular Surface Research and Education Foundation, Miami, FL, USA

${ }^{2}$ State Key Laboratory of Ophthalmology, Zhongshan Ophthalmic Center, Ocular

Surface Disease Center, Sun Yat-sen University,

Guangzhou, China

${ }^{3}$ Research Institute of Ophthalmology, Cairo, Egypt

${ }^{4}$ Department of Ophthalmology, The First Affiliated Hospital of Guangzhou Medical College, Guangzhou, China

Correspondence: SCG Tseng, Department of Tissue Tech., Ocular Surface Center, 7000 SW 97 Avenue, Suite 213, Miami, FL 33173, USA

Tel: + 305274 1299;

Fax: + 3052741297

E-mail: stseng@

ocularsurface.com

Received: 30 August 2008 Accepted in revised form:

11 September 2008

Published online: 19

December 2008

\title{
Limbal stem cell transplantation: new progresses and challenges
}

\begin{abstract}
Patients with limbal stem cell deficiency (LSCD) suffer from photophobia and a severe loss of vision uncorrectable by conventional PKP. This literature review shows that new strategies can be formulated for treating LSCD. Early cryopreserved amniotic membrane transplantation (AMT) as a temporary biological bandage with sutures or with sutureless ProKera ${ }^{\mathrm{TM}}$ in the acute stage of chemical burn and Stevens-Johnson syndrome prevents the occurrence of LSCD by preserving and expanding the remaining limbal epithelial stem cells. Similarly, remaining limbal stem cells can also be expanded in corneal surfaces with partial or nearly total LSCD if corneal pannus is removed and AMT is performed as a graft with or without sutures by the use of fibrin glue. Moreover, AMT as a temporary bandage and a graft using fibrin glue can also facilitate corneal surface reconstruction by reducing the size of a conjunctival limbal autograft (CLAU) to one $60^{\circ}$ graft for unilateral total LSCD as well as promote the success of a keratolimbal allograft (KLAL) for bilateral total LSCD. The latter success is further dictated by effective systemic immunosuppression and by measures to restore the ocular surface defenses, suppress conjunctival inflammation, and correct cicatricial complications so that a stable tear film can be maintained before surgery. This review also summarizes recent findings and outlines future challenges that we need to overcome in squamous metaplasia, that is, another major type of ocular surface failure. Eye (2009) 23, 1946-1953; doi:10.1038/eye.2008.379; published online 19 December 2008
\end{abstract}

Keywords: amniotic membrane; conjunctival limbal autograft; immunosuppression; keratolimbal allograft; limbal stem cell deficiency; sutureless
L Liang ${ }^{1,2}$, H Sheha ${ }^{1,3}, \mathrm{~J} \mathrm{Li}^{1,4}$ and SCG Tseng

Limbal stem cell (SC) deficiency (LSCD) and squamous metaplasia are two major types of ocular surface failure

A healthy cornea is covered by a stratified nonkeratinizing epithelium, which helps support a stable preocular tear film and forms a barrier against the pathogen entrance. The renewal of the corneal epithelium is governed by SCs exclusively located in the limbus clinically recognized as palisades of Vogt. ${ }^{1,2}$ Molecular mechanism for regulating limbal epithelial SCs remains unclear despite cumulative evidence indicating that their function is influenced by their surrounding microenvironment, the socalled limbal SC niche (for reviews see references $^{3-7}$ ).

When corneal limbal SCs are destroyed or the limbal SC niche is dysfunctional, a pathologic state known as LSCD may emerge. A number of hereditary and acquired diseases have been found to manifest LSCD, which carries the hallmark of conjunctivalization, that is, the corneal surface is covered by ingrowing conjunctival epithelium containing goblet cells (for reviews see Puangsricharern and Tseng 8 and Dua $e t a l^{9}$ ). Besides conjunctivalization, limbal deficient corneas also carry other pathologic features, such as destruction of the basement membrane, emergence of superficial neovascularization, chronic stromal inflammation, and scarring. Therefore, LSCD constitutes one major type of ocular surface failure leading to corneal blindness.

The other major type of ocular surface failure is caused by squamous metaplasia, where corneal as well as conjunctival epithelia turn into a stratified, non-secretory, keratinized epithelium. Unlike LSCD, the pathogenesis for squamous metaplasia is less understood. Recently, we investigated corneal pannus tissues from patients with severe ocular surface diseases manifesting squamous metaplasia and noted that such squamous metaplasia is 
coupled with cellular hyperproliferation, stratification, and keratinization, and the downregulation of Pax 6, which is a master gene dictating eye development, expressed by normal ocular surface epithelia, and playing a role in regulating the expression of corneaspecific keratin $12 .{ }^{10}$ Using normal limbal explants as a model, we further discovered that exposure them to the air-medium interface during cultivation is sufficient to induce squamous metaplasia only in the limbal, but not corneal, region, and that such an event is coupled with a transient loss of Pax 6 and can be reversed by addition of a p38 MAP kinase inhibitor. ${ }^{11}$ Taken together, these new findings indicate that squamous metaplasia of the ocular surface epithelium is linked with a pathologic process characterized by the downregulation of Pax 6. Future studies are needed to discern whether such a process represents reversible reactive or permanent intrinsic alteration of limbal SCs. Resolution of this question will lead to a new therapeutic approach for treating squamous metaplasia.

\section{Diagnosis of LSCD}

Accurate diagnosis and grading of the severity is crucial for planning an effective surgical strategy for LSCD. Although correct diagnosis of LSCD leads to successful visual rehabilitation, less appreciated is that casual diagnosis of LSCD without cytologic confirmation can be detrimental by subjecting the patient to unnecessary transplantation of allogeneic limbal SCs, and potentially toxicity from systemic immunosuppression. Among all signs of LSCD, only conjunctivalization, evidenced by goblet cell migrating onto the corneal surface, is specific for the diagnosis. The clinical clues of conjunctivalization can be suggested by the loss of limbal palisades of Vogt under slit-lamp examination or by late fluorescein staining of the cornea, which reflects poor epithelial barrier function. But definitive detection of conjunctivalization relies on impression cytology. ${ }^{8}$ Other signs, such as superficial vascularization, chronic inflammation, irregular epithelium, recurrent erosion, and persistent epithelial defect with/without ulceration, can also be observed in many other corneal diseases without LSCD. However, even if impression cytology is used, conjunctival goblet cells detected by PAS staining are not always detected in patients with clinically suspected LSCD, especially in such diseases as severe chemical burn, cicatricial ocular phenphygoid, or Stevens-Johnson syndrome (SJS). This notion, first recognized by Puangsricharem et $a l^{8}$ in 1995, was also recently noted by Fatima et $a l^{12}$ during their review of histopathologic changes of the ocular surface pannus in 29 patients with clinically diagnosed LSCD caused by chemical burns. It remains to be determined whether in vivo confocal microscopy can be more precise than impression cytology by looking into both superficial and basal epithelial layers. Future challenge rests on delineating a biomarker that is expressed not by cellular differentiation, hence present on the suprabasal layers, such as goblet cells or keratinization, but by stemness inherently present at the basal SC level.

\section{New progresses of surgical strategies}

\section{LSCD can be prevented by early intervention of amniotic} membrane transplantation (AMT)

As LSCD remains a major challenge for ophthalmologists, it will be a significant advance if its occurrence can be avoided at all cost during acute insults to limbal SCs in such diseases as chemical burns and SJS with or without toxic epidermal necrolysis (TEN). Even if fluorescein staining depicts an ocular surface defect involving the limbus, it does not ascertain that limbal SCs are completely destroyed at the basal level. Persistent inflammation has been recognized as a major threat leading to LSCD in humans ${ }^{8}$ and failure of autologous limbal conjunctival transplantation in rabbits. ${ }^{13}$ Therefore, without effective measures to suppress inflammation, even healthy limbal SCs will surely decline; let alone if they are already compromised by the aforementioned insults. On the basis of this line of reasoning, application of cryopreserved AM as a biological bandage to suppress inflammation represents a major advance in managing acute chemical burns. Several studies have deployed AMT in less than one day to 4 weeks following the burn. ${ }^{14-21}$ To address the question how soon AMT should be performed, Prabhasawat et $a l^{22}$ reported that AMT performed within 5 days of Grades II and III chemical burns resulted in faster epithelial healing and less corneal haze and LSCD than that performed after 5 days. Lately, ProKera ${ }^{\mathrm{TM}}$, an FDA-approved class II medical device consisting a sheet of cryopreserved AM clipped into a dual symblepharons ring system, was inserted to deliver the anti-inflammatory action of AM without delay in five eyes presented with total or extensive (60-75\%) corneal epithelial defects with $\left(90-360^{\circ}\right)$ limbal and (30-60\%) conjunctival epithelial defects within 8 days after chemical burn. ${ }^{23}$ Conjunctival defects were reepithelialized in $8.2 \pm 5$ (range, 5-17) days, whereas limbal/corneal defects healed in 13.6 \pm 8.3 (range, 5-25) days. This beneficial effect was uniquely shown by early complete closure of the perilimbal conjunctival defect before circumferential closure of the limbal defects followed by centripetal healing of the corneal defect. Early peripheral corneal neovascularization followed by marked regression upon healing was noted in three eyes. 
During $15 \pm 8.8$ months of follow-up, all eyes retained a stable corneal surface with improved clarity without LSCD or symblepharon. Whenever AM became cloudy due to the accumulation of inflammatory debris, ProKera also facilitates the ease of instant exchange. Therefore, this new sutureless approach of AMT allows not only early intervention but also repeatable delivery without delay of highly desired anti-inflammatory actions. As a result, remaining limbal SCs are preserved to elicit their enormous capacity of regeneration, and cicatricial complications, such as symblepharon, are prevented in the chronic stage for mild-to-moderate chemical burns.

The promising results of AMT in acute chemical burn shed lights on the treatment of other severe ocular surface diseases, such as SIS/TEN, that are also characterized by relentless inflammation in the acute stage. If left untreated, persistent inflammation in SJS/TEN not only further destroys limbal SCs, but also leads to the cicatricial sequelae of the eye lid and the tarsus, of which both are highly correlated with corneal blindness. ${ }^{24}$ When AMT is applied as a temporary biological bandage within 2 weeks following the acute episode of skin eruption, it has successfully treated 12 eyes of six patients with acute SJS/TEN during the period from 2002 to $2007^{24-28}$ (and also see a recent review by Gregory ${ }^{29}$ ). For a median follow-up of 9 months (ranging from 4 to 36 months) after AMT, none of those patients showed any persistent conjunctival inflammation. As a result, the entire ocular surface remains stable without developing LSCD. ProKera has also been inserted at day 5 (one eye) and day 10 (two eyes) after the onset of eye symptoms in three eyes with total corneal epithelial defects, and at day 27 in one eye with partial epithelial defect in two paediatric patients with SJS whose medical condition is too severe to let them be brought to the operation room. ${ }^{30}$ In a follow-up of 9 months for one patient and 20 months for the other, insertion of ProKera resulted in complete reepithelialization, clear corneas, and vision of 20/20 in all four eyes. However, due to the size limitation, cicatricial changes still occurred in the fornix, the tarsus, and the lid margin. Collectively, these results support the usefulness of early intervention of AMT as a new strategy for abating ocular surface inflammation, known to be relentless otherwise, so that LSCD can be prevented in these devastating ocular surface diseases.

\section{Partial and even nearly total LSCD can be treated by AMT} alone

Corneas with preexisting LSCD are managed according to the extent of LSCD and whether one or both eyes are affected (for reviews see references ${ }^{4,31,32}$ ). When LSCD is partial, where a part of the limbus is damaged, the corneal surface can be reconstructed by the removal of conjunctivalized epithelial tissue with or without AMT. ${ }^{33-35}$ It remains unclear to what extent of limbal involvement LSCD can still be treated by this strategy without limbal SC transplantation. Most recently, we reported our clinical experiences in performing superficial keratectomy to remove the conjunctivalized pannus followed by AMT using fibrin glue in 11 eyes of nine patients that had LSCD involving as large as $120^{\circ}$ to almost $360^{\circ}$ limbus. ${ }^{36}$ For a mean follow-up of 14.2 months (range, 6-26), all eyes regained a smooth and stable corneal epithelial surface without recurrent erosion or persistent epithelial defect, and showed less stromal cloudiness and vascularization. As a result, nine eyes showed improved best-corrected visual acuity. It is worth mentioning that in an eye with $240^{\circ}$ LSCD, a stage-wise surgical approach was adopted. The first surgery included removal of the pannus from the most involved area. After the healing was completed resulting in a full recovery of the limbal and corneal surfaces at the surgical areas, the second surgery was performed to remove the residual pannus from the remaining, less involved areas. As a result, the cornea recovered a stable and smooth epithelium without vascularization and much less cloudiness eventually. This encouraging result suggested the possibility of expanding remaining limbal SCs in vivo through this approach. Besides finding a better way of defining the extent of LSCD as mentioned above, future studies are needed to determine whether the aforementioned success is attributed to the use of fibrin glue, which prolongs the therapeutic actions of AM by delaying AM dissolution more so than sutures.

How small of conjunctival limbal autograft (CLAU) can still treat unilateral total LSCD?

For eyes inflicted with unilateral total LSCD, where the entire limbal circumference is damaged in one eye, corneal surface reconstruction resorts to transplantation of autologous limbal SCs in a procedure termed CLAU ${ }^{37}$ (and also see references ${ }^{38-41}$ for reviews). Because of the autologous source of limbal SCs, there is no risk of immune rejection and hence no need for any immunosuppression. A number of studies have shown overwhelming (greater than $80 \%$ ) successful visual outcomes with regression of neovascularization and improvement of corneal transparency after CLAU (Table 1, listed according to the year of publication). ${ }^{33,37,42-48}$ Originally, CLAU involves the removal of two large free grafts, each spanning from 5 to $7 \mathrm{~mm}$ in the limbal arc length, that is, $240^{\circ}$, from the healthy fellow eye. ${ }^{37}$ Therefore, there is always a concern whether the donor eye will develop LSCD in the long 
Table 1 Literature summary of CLAU for total LSCD

\begin{tabular}{|c|c|c|c|c|c|c|c|}
\hline \multirow[t]{2}{*}{ Authors } & \multirow[t]{2}{*}{ Cases } & \multirow{2}{*}{$\begin{array}{c}\text { Median FU } \\
\text { (months) }\end{array}$} & \multirow{2}{*}{$\begin{array}{l}\text { Improved } \\
V A(\%)\end{array}$} & \multirow{2}{*}{$\begin{array}{l}\text { Improved } \\
\text { surface (\%) }\end{array}$} & \multicolumn{2}{|c|}{ CLAU size } & \multirow[t]{2}{*}{ With AMT } \\
\hline & & & & & Successful & Failure & \\
\hline Kenyon and Tseng ${ }^{37}$ & 21 & 23 & 81 & 95 & $240^{\circ}$ & NA & $\mathrm{N}$ \\
\hline Rao et $a l^{42}$ & 16 & NA & 69 & 94 & $60-90^{\circ}$ & $60^{\circ}$ & $\mathrm{N}$ \\
\hline Moldovan $e t a l^{43}$ & 5 & 24 & 25 & 80 & $90-160^{\circ}$ & $80^{\circ}$ & $\mathrm{N}$ \\
\hline Dua and Azuara-Blanco ${ }^{33}$ & 6 & 19 & 100 & 100 & $120^{\circ}$ & NA & $\mathrm{N}$ \\
\hline Meallet et $a l^{44}$ & 5 & 22 & 100 & 100 & $240^{\circ}$ & NA & $\mathrm{Y}$ \\
\hline Ivekovic et $a l^{45}$ & 6 & 16 & 100 & 100 & $180^{\circ}$ & NA & $\mathrm{Y}$ \\
\hline Santos et $a l^{46}$ & 10 & 33 & NA & 80 & $120^{\circ}$ & NA & $\mathrm{Y}$ \\
\hline Kheirkhah et $a l^{47}$ & 1 & 12 & 100 & 100 & $60^{\circ}$ & NA & $\mathrm{Y}$ \\
\hline
\end{tabular}

$\mathrm{CLAU}=$ conjunctival limbal autograft; $\mathrm{FU}=$ follow-up; $\mathrm{LSCD}=$ limbal stem cell deficiency; $\mathrm{N}=$ no; $\mathrm{NA}=$ not applicable; $\mathrm{VA}=$ visual acuity; $\mathrm{Y}=$ yes.

run, as suggested in the experimental rabbit studies. ${ }^{49,50}$ Presumably to avoid the above concern, a smaller size of CLAU as $90-160^{\circ}$ were used, but a comparable success rate was not achieved if the size was reduced to $90^{\circ}$ or less (Table 1). Importantly, when these smaller grafts were used, several complications have been noted in donor eye including localized haze, ${ }^{33}$ pseudopterygium, ${ }^{51,52}$ filamentary keratitis, ${ }^{42}$ microperforation during surgery, ${ }^{53}$ abnormal epithelium, ${ }^{54}$ and corneal depression. ${ }^{55}$

Knowing that AMT as a biological bandage can facilitate in vivo expansion of remaining limbal SCs, ${ }^{14,16,18}$ we and others have incorporated AMT during CLAU to promote a higher success rate while circumventing aforementioned complications to donor eyes. ${ }^{44-46}$ However, all these studies did not attempt to address whether a smaller size of CLAU can still be sufficient. As mentioned above, because AMT with fibrin glue performed in stages can even help treat nearly total LSCD ${ }^{36}$ we examined the hypothesis that one $60^{\circ} \mathrm{CLAU}$, if combined with insertion of ProKera as well as with AMT using fibrin glue, might be sufficient to restore the corneal surface with unilateral total LSCD. ${ }^{47}$ In a single case report, we noted that the corneal epithelialization was completed by day 18 after surgery. During a followup of 1 year, the corneal surface remained stable and smooth, and the stroma considerably regained clarity with the regression of midstromal vascularization. The best-corrected visual acuity improved from 20/400 to $20 / 50$. The conjunctival inflammation completely resolved, and the fornices were deep. No complication was noted in the donor eye. Therefore, a combination of AMT as a permanent graft and as a temporary patch might act together to secure an (fetal) environment favourable for the regeneration of limbal SCs. Additional trials are needed to determine whether our observation can be uniformly applied to all eyes with unilateral total LSCD.
How can we further improve the long-term outcome of keratolimbal allograft (KLAL)?

In the event of bilateral or unilateral total LSCD, transplantation of allogeneic limbal SCs is the only remaining alternative for successful corneal surface restoration. This can be achieved by KLAL from cadaveric donors ${ }^{56-58}$ or by limbal conjunctival allograft from living-related donors (lr-CLAL) ${ }^{58,59} \mathrm{~A}$ KLAL is a $360^{\circ}$ lamellar ring graft encompassing a minimal portion of scleral tissue, the entire limbus, and the most peripheral portion of the cornea. When compared with lr-CLAL, KLAL offers the advantages of providing $360^{\circ}$ SC supply because the entire eye limbal circumference is used for reconstruction, and thus eliminating the concern of removing healthy limbal tissue from a normal eye, but still carried the disadvantages of lacking in the conjunctival tissue for simultaneous conjunctival reconstruction.

Although the short-term success rate of KLAL are comparable to those of CLAU, when the follow-up period is prolonged to more than 2 years, the success rate of KLAL dramatically drops to less than $60 \%$ (Table 2, listed according to the median follow-up length). ${ }^{55,56,60-69}$ This discrepancy is in great contrast to the overwhelmingly high success achieved by CLAU (Table 1). One natural explanation for the failure of KLAL is allograft rejection because transplantation is carried out to the limbus, a highly vascularized area relatively abundant in Langerhans' cells. However, even under continuous systemic administration of cyclosporine A alone with or without steroid, the long-term results for KLAL over 3 years of follow-up remained unsatisfactory (Table 2). ${ }^{63-68}$ In the past 8 years, we have used a combined immunosuppressive regimen including systemic $0.5 \mathrm{mg} / \mathrm{kg} /$ day FK506 starting 1 week as well as $0.5 \mathrm{mg} / \mathrm{kg} /$ day prednisone, $2 \mathrm{~g} /$ day MMF, and $200 \mathrm{mg}$ $5 /$ day acyclovir prophylactically against viral reactivation, starting 3 days before surgery in 10 patients 
Table 2 Literature summary of KLAL for total LSCD

\begin{tabular}{|c|c|c|c|c|c|}
\hline Authors & Cases & $\begin{array}{c}\text { Median FU } \\
\text { (months) }\end{array}$ & $\begin{array}{c}\text { Visual } \\
\text { improvement (\%) }\end{array}$ & $\begin{array}{c}\text { Surface } \\
\text { improvement (\%) }\end{array}$ & Immunosuppression \\
\hline Dua and Azuara-Blanco ${ }^{60}$ & 6 & 11.8 & 84 & 100 & Tacrolimus \\
\hline Tsubota et al ${ }^{61}$ & 9 & 12 & 100 & 100 & $\begin{array}{l}\text { CsA } \\
\text { Dexamethasone }\end{array}$ \\
\hline Tan et $a l^{55}$ & 9 & 14 & 100 & 77 & CsA \\
\hline Gomes et $a l^{35}$ & 10 & 16.7 & 40 & 20 & $\begin{array}{l}\text { CsA } \\
\text { Prednisone }\end{array}$ \\
\hline Tsai and Tseng ${ }^{56}$ & 16 & 18.5 & 82 & 100 & CsA \\
\hline Tsubota et al ${ }^{63}$ & 43 & 23 & 60 & 51 & $\begin{array}{l}\text { CsA } \\
\text { Dexamethasone }\end{array}$ \\
\hline Holland $^{64}$ & 25 & 27 & 66 & 62 & CsA \\
\hline Solomon et al ${ }^{65}$ & 39 & 34 & 44.6 & 23.7 & CsA \\
\hline Holland et $a l^{66}$ & 31 & 36 & 83.9 & 74.2 & $\begin{array}{l}\text { CsA } \\
\text { Prednisone }\end{array}$ \\
\hline Maruyama-Hosoi et al ${ }^{69}$ & 85 & 46 & NA & 55.3 & CsA \\
\hline Ilari and Daya ${ }^{67}$ & 23 & 60 & 43.5 & 27.3 & CsA \\
\hline Shimazaki et al $l^{68}$ & 29 & 72 & 48 & 45 & $\begin{array}{l}\text { CsA } \\
\text { Dexamethasone }\end{array}$ \\
\hline
\end{tabular}

$\mathrm{CsA}=$ cyclosporine $\mathrm{A} ; \mathrm{FU}=$ follow-up; $\mathrm{KLAL}=$ keratolimbal allograft; $\mathrm{LSCD}=$ limbal stem cell deficiency. Improved surface is defined as epithelialization and improvement in corneal clarity and smoothness.

receiving KLAL for bilateral total LSCD (eight patients) and unilateral total LSCD (two patients). Both prednisone and acyclovir were tapered off in 2-3 months after surgery when the eye became quiet. Their doses were adjusted according to the balance between ocular surface inflammation and the systemic side effects known for MMF and FK506 according to the levels of creatinine and BUN, CBC, platelets, and liver profile. Patients with notable systemic diseases and taking other systemic medications were also monitored by internists to ensure systemic well-being. In our 10 cases, MMF was given at $0.8-2 \mathrm{~g} /$ day and FK506 at $1.1-3 \mathrm{~g} /$ day, and the trough levels of MMF and FK506 were checked at the frequency of monthly to quarterly for the first year. The mean trough level was $1.6 \mu \mathrm{g} / \mathrm{ml}$ and $4.5 \mathrm{ng} / \mathrm{ml}$ for MMF and FK506, respectively. Although both doses and levels are lower than those used for solid organ transplantation, we noted seven episodes of KLAL graft rejection in six eyes (50\%; all successfully reversed), and four episodes of PKP graft rejection in three eyes (30\%; two successfully reversed) during a mean follow-up of $50.3 \pm 14.1$ months (range, 36-84). Our overall KLAL rejection rate is much reduced when compared to earlier studies using cyclosporin A alone. ${ }^{63-68}$

Allograft rejection does not account for all KLAL failure ${ }^{67-69}$ Severe dry eye ${ }^{46,68}$ keratinization, ${ }^{58,70}$ chronic inflammation, ${ }^{71}$ and uncorrected lid and lid margin abnormalities ${ }^{46}$ have all been found associated with poor prognosis for KLAL (for review see Espana et $a l^{31}$ ). That was why eyes with SJS/TEN, which tend to cumulate many of these deficits, have the poorest long-term outcome of KLAL. ${ }^{63,65,68}$ In our 10 patients (12 eyes) receiving KLAL, one was caused by SJS/TEN, one by an unknown cause, and the remaining 10 were caused by chemical burns. We identified deficits in the ocular surface defense, such as exposure problem, that is, incomplete blinking, reduced blinking rate, or lagophthalmos (10 eyes), dry eye (9 eyes), glaucoma (6 eyes), mechanical insults due to trichiasis, distichiasis, keratinization of the lid margin, or entropion (5 eyes), and symblepharon (5 eyes).

Because we and others have proposed that it is a prerequisite to restore a sound ocular surface defense before $\mathrm{KLAL}^{31,46,65,67}$ we performed epilation and bandage contact lens (12 eyes), tarsorrhaphy (11 eyes), punctal occlusion (11 eyes), autologous serum drops (9 eyes), symblepharon lysis, fornix reconstruction and AMT (4 eyes) ${ }^{72}$, and lid reconstruction (3 eyes). Intraocular pressure was also controlled by glaucoma drainage implant surgery or by medications before KLAL. For visual rehabilitation, penetrating keratoplasty was performed in 10 of 12 eyes at $9.6 \pm 9.2$ months after KLAL (range, 1-31). For a mean follow-up of $50.3 \pm 14.1$ months, nine eyes $(75 \%)$ gained a clear cornea with a stable epithelium. The visual acuity improved from non-ambulatory (hand movement, $20 / 200)$ to ambulatory (20/200-20/20) at the last visit in these nine eyes. Our overall success rate is better than that of an earlier study, in which only patients with aniridia lacking most of these deficits were included. ${ }^{66}$ 
Therefore, we sumarise that meticulous restoration of the ocular surface defense together with a combined immunosuppressive regimen can further improve the long-term visual outcome of KLAL and PKP. Future discovery of more effective therapies for reversing squamous metaplasia and suppressing relentless ocular surface inflammation will surely further improve the KLAL outcome.

\section{Acknowledgements}

This study was supported by grants from the Technological Project Foundation of Guangdong Province (2006B36006002) and Medical Science Fund of Guangdong Province (B2006061). Dr Tseng and his family are more than 5\% shareholders of TissueTech. Inc., which owns US patents 6152142 and 6326019 on the method of preparation and clinical uses of human amniotic membrane and ProKera ${ }^{\mathrm{TM}}$ distributed by Bio-Tissue Inc. No other author has any proprietary/ financial interest in any material or method mentioned in this study.

This paper was presented at the Cambridge Ophthalmological Symposium, 3-5 September 2008.

\section{References}

1 Schermer A, Galvin S, Sun T-T. Differentiation-related expression of a major $64 \mathrm{~K}$ corneal keratin in vivo and in culture suggests limbal location of corneal epithelial stem cells. J Cell Biol 1986; 103: 49-62.

2 Cotsarelis G, Cheng SZ, Dong G, Sun T-T, Lavker RM. Existence of slow-cycling limbal epithelial basal cells that can be preferentially stimulated to proliferate: implications on epithelial stem cells. Cell 1989; 57: 201-209.

3 Tseng SCG. Regulation and clinical implications of corneal epithelial stem cells. Mol Biol Rep 1996; 23: 47-58.

4 Dua HS, Jagjit SS, Azuara-Blanco A, Gupta P. Limbal stem cell deficiency: concept, aetiology, clinical presentation, diagnosis and management. Indian J Ophthalmol 2000; 48: 83-92.

5 Lavker RM, Tseng SC, Sun TT. Corneal epithelial stem cells at the limbus: looking at some old problems from a new angle. Exp Eye Res 2004; 78: 433-446.

6 Schlotzer-Schrehardt U, Kruse FE. Identification and characterization of limbal stem cells. Exp Eye Res 2005; 81: 247-264.

7 Li W, Hayashida Y, Chen YT, Tseng SC. Niche regulation of corneal epithelial stem cells at the limbus. Cell Res 2007; 17: 26-36.

8 Puangsricharern V, Tseng SCG. Cytologic evidence of corneal diseases with limbal stem cell deficiency. Ophthalmology 1995; 102: 1476-1485.

9 Dua HS, Joseph A, Shanmuganathan VA, Jones RE. Stem cell differentiation and the effects of deficiency. Eye 2003; 17: 877-885.

10 Li W, Chen YT, Hayashida Y, Blanco G, Kheirkah A, He H et al. Down-regulation of Pax6 is associated with abnormal differentiation of corneal epithelial cells in severe ocular surface diseases. J Pathol 2008; 214: 114-122.

11 Li W, Hayashida Y, Chen YT, He H, Tseng DY, Alonso M et al. Air exposure induced squamous metaplasia of human limbal epithelium. Invest Ophthalmol Vis Sci 2008; 49: 154-162.

12 Fatima A, Iftekhar G, Sangwan VS, Vemuganti GK. Ocular surface changes in limbal stem cell deficiency caused by chemical injury: a histologic study of excised pannus from recipients of cultured corneal epithelium. Eye 2008; 22: 161-167.

13 Tsai RJF, Tseng SCG. Effect of stromal inflammation on the outcome of limbal transplantation for corneal surface reconstruction. Cornea 1995; 14: 439-449.

14 Meller D, Pires RTF, Mack RJS, Figueiredo F, Heiligenhaus A, Park WC et al. Amniotic membrane transplantation for acute chemical or thermal burns. Ophthalmology 2000; 107: 980-990.

15 Kim JS, Kim JC, Na BK, Jeong JM, Song CY. Amniotic membrane patching promotes healing and inhibits protease activity on wound healing following acute corneal alkali burns. Exp Eye Res 2000; 70: 329-337.

16 Sridhar MS, Bansal AK, Sangwan VS, Rao GN. Amniotic membrane transplantation in acute chemical and thermal injury. Am J Ophthalmol 2000; 130: 134-137.

17 Ucakhan OO, Koklu G, Firat E. Nonpreserved human amniotic membrane transplantation in acute and chronic chemical eye injuries. Cornea 2002; 21: 169-172.

18 Kobayashi A, Shirao Y, Yoshita T, Yagami K, Segawa Y, Kawasaki $\mathrm{K}$ et al. Temporary amniotic membrane patching for acute chemical burns. Eye 2003; 17: 149-158.

19 Arora R, Mehta D, Jain V. Amniotic membrane transplantation in acute chemical burns. Eye 2005; 19: 273-278.

20 Tamhane A, Vajpayee RB, Biswas NR, Pandey RM, Sharma $\mathrm{N}$, Titiyal JS et al. Evaluation of amniotic membrane transplantation as an adjunct to medical therapy as compared with medical therapy alone in acute ocular burns. Ophthalmology 2005; 112: 1963-1969.

21 Tejwani S, Kolari RS, Sangwan VS, Rao GN. Role of amniotic membrane graft for ocular chemical and thermal injuries. Cornea 2007; 26: 21-26.

22 Prabhasawat P, Tesavibul N, Prakairungthong N, Booranapong W. Efficacy of amniotic membrane patching for acute chemical and thermal ocular burns. J Med Assoc Thai 2007; 90: 319-326.

23 Kheirkhah A, Johnson DA, Paranjpe DR, Raju VK, Casas V, Tseng SCG. Temporary sutureless amniotic membrane patch for acute alkaline burns. Arch Ophthalmol. 2007; 126: 1059-1066.

24 Di Pascuale MA, Espana EM, Liu DT, Kawakita T, Li W, Gao YY et al. Correlation of corneal complications with eyelid cicatricial pathologies in patients with Stevens-Johnson syndrome and toxic epidermal necrolysis syndrome. Ophthalmology 2005; 112: 904-912.

25 John T, Foulks GN, John ME, Cheng K, Hu D. Amniotic membrane in the surgical management of acute toxic epidermal necrolysis. Ophthalmology 2002; 109: 351-360.

26 Kobayashi A, Yoshita T, Sugiyama K, Miyashita K, Niida Y, Koizumi $S$ et al. Amniotic membrane transplantation in acute phase of toxic epidermal necrolysis with severe corneal involvement. Ophthalmology 2006; 113: 126-132.

27 Muqit MM, Ellingham RB, Daniel C. Technique of amniotic membrane transplant dressing in the management of acute Stevens-Johnson syndrome. Br J Ophthalmol 2007; 91: 1536. 
28 Tandon A, Cackett P, Mulvihill A, Fleck B. Amniotic membrane grafting for conjunctival and lid surface disease in the acute phase of toxic epidermal necrolysis. J AAPOS 2007; 11: 612-613.

29 Gregory DG. The ophthalmologic management of acute Stevens-Johnson syndrome. Ocul Surf 2008; 6: 87-95.

30 Shay E, Kheirkhah A, Liang L, Sheha H, Gregory DG, Tseng SCG. Amniotic membrane transplantation as a new therapy for acute Stevens-Johnson syndrome. Surv Ophthalmol 2008 (in press).

31 Espana EM, Di Pascuale M, Grueterich M, Solomon A, Tseng SCG. Keratolimbal allograft for corneal surface reconstruction. Eye 2004; 18: 406-417.

32 Fernandes M, Sangwan VS, Rao SK, Basti S, Sridhar MS, Bansal AK et al. Limbal stem cell transplantation. Indian J Ophthalmol 2004; 52: 5-22.

33 Dua HS, Azuara-Blanco A. Autologous limbal transplantation in patients with unilateral corneal stem cell deficiency. Br J Ophthalmol 2000; 84: 273-278.

34 Anderson DF, Ellies P, Pires RT, Tseng SC. Amniotic membrane transplantation for partial limbal stem cell deficiency. Br J Ophthalmol 2001; 85: 567-575.

35 Gomes JA, dos Santos MS, Cunha MC, Mascaro VL, Barros JN, de Sousa LB. Amniotic membrane transplantation for partial and total limbal stem cell deficiency secondary to chemical burn. Ophthalmology 2003; 110: 466-473.

36 Kheirkhah A, Casas V, Raju VK, Tseng SC. Sutureless amniotic membrane transplantation for partial limbal stem cell deficiency. Am J Ophthalmol 2008; 145: 787-794.

37 Kenyon KR, Tseng SC. Limbal autograft transplantation for ocular surface disorders. Ophthalmology 1989; 96: 709-722.

38 Tan D. Conjunctival grafting for ocular surface disease. Curr Opin Ophthalmol 1999; 10: 277-281.

39 Basti S, Rao SK. Current status of limbal conjunctival autograft. Curr Opin Ophthalmol 2000; 11: 224-232.

40 Kruse FE, Reinhard T. Limbus transplantation for reconstruction of the ocular surface. Ophthalmologe 2001; 98: 818-831.

41 Gruterich M, Tseng SC. Surgical approaches for limbal stem cell deficiency. Klin Monatsbl Augenheilkd 2002; 219: 333-339.

42 Rao SK, Rajagopal R, Sitalakshmi G, Padmanabhan P. Limbal autografting: comparison of results in the acute and chronic phases ocular surface burns. Cornea 1999; 18: 164-171.

43 Moldovan SM, Borderie V, Baudrimont M, Laroche L. Treatment of unilateral limbal stem cell deficiency syndrome by limbal autograft. J Fr Ophtalmol 1999; 22: 302-309.

44 Meallet MA, Espana EM, Grueterich M, Ti S-E, Goto E, Tseng SCG. Amniotic membrane transplantation for recipient and donor eyes undergoing conjunctival limbal autograft for total limbal stem cell deficiency. Ophthalmology 2003; 110: 1585-1592.

45 Ivekovic R, Tedeschi-Reiner E, Novak-Laus K, ndrijevicDerk B, Cima I, Mandic Z. Limbal graft and/or amniotic membrane transplantation in the treatment of ocular burns. Ophthalmologica 2005; 219: 297-302.

46 Santos MS, Gomes JA, Hofling-Lima AL, Rizzo LV, Romano AC, Belfort Jr R. Survival analysis of conjunctival limbal grafts and amniotic membrane transplantation in eyes with total limbal stem cell deficiency. Am J Ophthalmol 2005; 140: 223-230.

47 Kheirkhah A, Raju VK, Tseng SC. Minimal conjunctival limbal autograft for total limbal stem cell deficiency. Cornea 2008; 27: 730-733.
48 Gatinel D, Nghiem MH, Chaine G. Early limbal autograft after alkali burn of the ocular surface. J Fr Ophtalmol 1999; 22: 76-78.

49 Chen JJY, Tseng SCG. Corneal epithelial wound healing in partial limbal deficiency. Invest Ophthalmol Vis Sci 1990; 31: 1301-1314.

50 Chen JJY, Tseng SCG. Abnormal corneal epithelial wound healing in partial thickness removal of limbal epithelium. Invest Ophthalmol Vis Sci 1991; 32: 2219-2233.

51 Gris O, Guell JL, Del Campo Z. Limbal-conjunctival autograft transplantation for the treatment of recurrent pterygium. Ophthalmology 2000; 107: 270-273.

52 Jenkins C, Tuft S, Liu C, Buckley R. Limbal transplantation in the management of chronic contact-lens-associated epitheliopathy. Eye 1993; 7: 629-633.

53 Basti S, Mathur U. Unusual intermediate-term outcome in three cases of limbal autograft transplantation. Ophthalmology 1999; 106: 958-963.

54 Morgan S, Murray A. Limbal autotransplantation in the acute and chronic phases of severe chemical injuries. Eye 1996; 10: 349-354.

55 Tan DTH, Ficker LA, Buckley RJ. Limbal transplantation. Ophthalmology 1996; 103: 29-36.

56 Tsai RJF, Tseng SCG. Human allograft limbal transplantation for corneal surface reconstruction. Cornea 1994; 13: 389-400.

57 Tsubota K, Toda I, Saito H, Shinozaki N, Shimazaki J. Reconstruction of the corneal epithelium by limbal allograft transplantation for severe ocular surface disorders. Ophthalmology 1996; 102: 1486-1496.

58 Holland EJ, Schwartz GS. Epithelial stem-cell transplantation for severe ocular surface disease. $N$ Eng $J$ Med 1999; 340: 1752-1753.

59 Daya SM, Ilari L. Living related conjunctival limbal allograft for the treatment of stem cell deficiency. Ophthalmology 2001; 108: 126-134.

60 Dua HS, Azuara-Blanco A. Allo-limbal transplantation in patients with limbal stem cell deficiency. Br J Ophthalmol 1999; 83: 414-419.

61 Tsubota K, Toda I, Saito H, Shinozaki N, Shimazaki J. Reconstruction of the corneal epithelium by limbal allograft transplantation for severe ocular surface disorders. Ophthalmology 1995; 102: 1486-1496.

62 Gomes JA, Santos MS, Ventura AS, Donato WB, Cunha MC, Hofling-Lima AL. Amniotic membrane with living related corneal limbal/conjunctival allograft for ocular surface reconstruction in Stevens-Johnson syndrome. Arch Ophthalmol 2003; 121: 1369-1374.

63 Tsubota K, Satake Y, Kaido M, Shinozaki N, Shimmura S, Bissen-Miyajima $\mathrm{H}$ et al. Treatment of severe ocular surface disorders with corneal epithelial stem-cell transplantation. N Eng J Med 1999; 340: 1697-1703.

64 Holland EJ. Epithelial transplantation for the management of severe ocular surface disease. Trans Am Ophthalmol Soc 1996; 94: 677-743.

65 Solomon A, Ellies P, Anderson DF, Touhami A, Grueterich M, Espana EM et al. Long-term outcome of keratolimbal allograft with or without penetrating keratoplasty for total limbal stem cell deficiency. Ophthalmology 2002; 109: 1159-1166.

66 Holland EJ, Djalilian AR, Schwartz GS. Management of aniridic keratopathy with keratolimbal allograft: a limbal stem cell transplantation technique. Ophthalmology 2003; 110: $125-130$ 
67 Ilari L, Daya SM. Long-term outcomes of keratolimbal allograft for the treatment of severe ocular surface disorders. Ophthalmology 2002; 109: 1278-1284.

68 Shimazaki J, Shimmura S, Fujishima H, Tsubota K. Association of preoperative tear function with surgical outcome in severe Stevens-Johnson syndrome. Ophthalmology 2000; 107: 1518-1523.

69 Maruyama-Hosoi F, Shimazaki J, Shimmura S, Tsubota K. Changes observed in keratolimbal allograft. Cornea 2006; 25: 377-382.
70 Holland EJ, Schwartz GS. The evolution of epithelial transplantation for severe ocular surface disease and a proposed classification system. Cornea 1996; 15: 549-556.

71 Samson CM, Nduaguba C, Baltatzis S, Foster CS. Limbal stem cell transplantation in chronic inflammatory eye disease. Ophthalmology 2002; 109: 862-868.

72 Solomon A, Espana EM, Tseng SCG. Amniotic membrane transplantation for reconstruction of the conjunctival fornices. Ophthalmology 2003; 110: 93-100. 